\title{
Relationship of Lower Extremity Muscle Strength with Balance and Lower Extremity Functions in Elderly Women
}

\section{Yaşlı Kadınlarda Alt Ekstremite Kas Kuvvetinin Denge ve Alt Ektremite Fonksiyonları ile İlişkisi}

\author{
Ferdi Başkurtt ${ }^{1}$, Sabriye Ercan², Zeliha Başkurt ${ }^{1}$ \\ ${ }^{1}$ Süleyman Demirel University Faculty of Health Sciences, Department of Physical Therapy and Rehabilitation, Isparta, Turkey \\ ${ }^{2}$ Dr. Ersin Arslan Education and Research Hospital, Department of Sports Medicine, Gaziantep, Turkey
}

F. Başkurt

0000-0002-8997-4172

S. Ercan

0000-0001-9500-698X

Z. Başkurt

0000-0001-7488-9242

Geliş Tarihi / Date Received: 15.10.2017

Kabul Tarihi / Date Accepted: 27.11.2017

Yayın Tarihi / Date Published: 02.03.2018

Yazışma Adresi /

Corresponding Author:

Sabriye Ercan

Dr. Ersin Arslan Eğitim ve Araştırma Hastanesi, Spor Hekimliği Bölümü,

Gaziantep, Turkey.

E-mail: sabriyeercan@gmail.com

(C)2018 Türkiye Spor Hekimleri Derneği. Tüm hakları saklıdır.

\begin{abstract}
Objective: The purpose of this study was to determine the relationships between strength of different muscle groups of the lower extremity, balance and lower extremity functions in women over 65 years.

Materials and Methods: A total of 72 voluntary women participated in the study. Falling story in the last year, age, body weight and height were recorded. Berg Functional Balance Scale, Functional Reach Test, Timed Up and Go Test, and Lower Extremity Functional Scale were evaluated. Muscle strength measurements in the lower extremity were performed with digital handheld dynamometer. The relationship between parameters in the elderly subjects was evaluated by Pearson correlation analysis. The Mann-Whitney $U$ test was used to determine the difference between the groups.

Results: Eight of the participants (11.1\%) had falling stories in the last year. Berg Functional Balance Scale score was 49.7 \pm 5.6 (32-56) points, Functional Reach Test score was 23.2 \pm 5.7 $(12-38) \mathrm{cm}$, Timed Up and Go Test score was 10.8 \pm 4.4 (4.2-33.3) s, and the Lower Extremity Functional Scale score was $39.6 \pm 15(12-79)$ points. All of the tests were associated with lower extremity muscle strength at different levels. Analyzed test parameters correlated with age ( $p^{<0.05)}$. Hip extensor, knee extensor and ankle dorsiflexor muscle strength, Timed Up and Go Test and Functional Reach Test results were worse in the group with falling stories $\left(p^{<} 0.05\right)$

Conclusions: Functional score, mobility and balance are related to lower extremity muscle strength in elderly women. Increasing muscle strength will reduce the risk of falls and increase independence.
\end{abstract}

Key Words: Muscle strength, balance, physical function

\section{öz}

Amaç: Bu çalışmanın amacı; 65 yaş üstü kadınlarda alt ekstremitede yer alan farklı kas gruplarına ilişkin kuvvetin, denge ve alt ekstremite fonksiyonları ile ilişkisini belirlemektir. Gereç ve Yöntemler: Çalışmaya 72 kadın gönüllü olarak katıldı. Katılımcıların yaşı, vücut ağırlığı, boy uzunluğu ve son bir yıl içindeki düşme öyküsü kaydedildi. Katılımcılara, Berg Fonksiyonel Denge Skalası, Fonksiyonel Uzanma Testi, Zamanlı Kalk ve Yürü Testi ve Alt Ekstremite Fonksiyonel Ölçeği uygulandı. Alt ekstremitede kas kuvveti ölçümü, dijital el dinamometresi kullanılarak yapıldı. Veriler arasındaki ilişkinin belirlenmesi için Pearson korrelasyon analizi kullanıldı. Gruplar arası farkı saptamada Mann-Whitney U testi kullanıldı. Bulgular: Katılımcıların sekizi (\%11.1) son bir yılda düşme öyküsüne sahipti. Berg Fonksiyonel Denge Skalası 49.7 \pm 5.6 (32-56) puan, Fonksiyonel Uzanma Testi $23.2 \pm 5.7$ $(12-38) \mathrm{cm}$, Zamanlı Kalk ve Yürü Testi 10.8 \pm 4.4 (4.2-33.3) s ve Alt Ekstremite Fonksiyonel 
Ölçeği 39.6 15 (12-79) puan olarak elde edildi. Yapılan testlerin tümü alt ekstremite kas kuvvetleri ile farklı düzeylerde

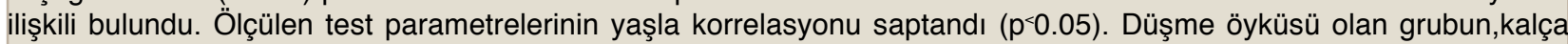
ekstansör, diz ekstansör ve ayak bileği dorsifleksör kas kuvveti, Zamanlı Kalk ve Yürü Testi ve Fonksiyonel Uzanma Testi sonuçları daha kötüydü $\left(p^{<} 0.05\right)$.

Sonuçlar: Yaşlı kadınlardaki fonksiyonelliğin, mobilitenin ve dengenin, alt ekstremite kasları kuvvetleri ile ilişkisi vardır. Kas kuvvetinin arttırıması, düşme riskini azaltıp bağımsızlığı arttıracaktır.

Anahtar Sözcükler: Kas kuvveti, denge, fiziksel işlev.

Available at: http://journalofsportsmedicine.org and http://dx.doi.org/10.5152/tjsm.2018.086

Cite this article as: Baskurt F, Ercan S, Baskurt Z. Relationship of lower extremity muscle strength with balance and lower extremity functions in elderly women Turk J Sports Med. 2018;53:17-26.

\section{GíRiș}

Sarkopeni, yaşlılarda görülen, kas kütlesindeki, gücündeki ve fonksiyonlarındaki kayıp olarak tanımlanan, klinik etkileri çok yüksek geriatrik bir sendromdur. Sendrom, hareket serbestliğinde azalmaya, düşmeye ve başkalarına bağımlılı̆̆a neden olarak hastanın yaşam kalitesine etki etmektedir (1). Yaşın ilerlemesi ile birlikte kasta sarkopeni gelişiminin yanı sıra sensörimotor nöron kaybı, tip 2 kas liflerinin atrofisi, osteoporoz gibi iskelet patolojileri, denge ve fonksiyon kaybına bağlı değișiklikler meydana gelmektedir (2-4). Yirmi yaş ile 70 yaş arasında, iskelet kası kütlesi kadınlarda \%11, erkeklerde \%15 oranında düşüş göstermekte (5) ve 60 yaş üstündeki bireylerde sarkopeni \%3-52 sıklıkta görülmektedir (6). Yaş ilerledikçe vestibüler sistemde, propriosepsiyonda, reaksiyon zamanında kayıplar gelişebilmektedir. $\mathrm{Bu}$ sistemlerdeki yetersizlikler ise denge kaybı ile sonuçlanabilmektedir $(7,8)$. Yaşlanmaya ve sarkopeniye bağlı kas kuvvetindeki ve fiziksel fonksiyonlardaki (yürüme hızı, denge, oturmakalkma performansı gibi) kayıpların düşme riski ile ilişkisi bulunmaktadır (9).

Çoğu araştırmacl, düşme riskini ve sıklığını azaltabilmek için sorunun kaynağını araştırmış ve çözüm önerileri geliştirmeye çalışmıştır (10). Çalışmaların birçoğu, lökomotor sistem ile düşme arasında güçlü bağlantı olduğunu ortaya koymuş, denge sistemindeki yetersizliklerin düşme ile ilişsisini tanımlamıştır $(7,10)$. Ayrıca, alt ekstremite kas kuvvetinin, gücünün ve fonksiyonlarının korunmasının, bağımsızlık ve genel yaşam kalitesinin yüksekliği ile doğrudan bağlantısı bulunmuştur (11).

Sandalyeden kalkabilme yeteneği, günlük hayatın kalitesini ve kişinin bağımsızlığını belirlemek konusunda fikir vericidir. Biyomekanik özellikleri belirlemeye yönelik olarak tasarlanan çalışmalarda, sandalyeden hızlı ve güvenle kalkıp dengeyi tekrar sağlayabilme yeteneğinde kalça çevresindeki kas grupları etkili bulunmuştur (12). Mobilitede ise anterior bölgedeki kas gruplarından ziyade gastroknemius, soleus, hamstring, gluteus medius/ minimus gibi posterior bölgedeki kasların önemli görevlerinin olduğu belirlenmiştir (13). Dengekas kuvveti bağlantısı ise alt ekstremite kas grupları için tanımlanmış ve özellikle kalça ekstansör, diz ekstansör ve fleksör, ayak bileği plantarfleksör kas gruplarının kuvveti bu bağlantıdan sorumlu tutulmuştur (14).

Kas kuvveti, denge ve fonksiyonellik ilişkilerinin tanımlanabilmesi, yaşlı bireylerin dengesinin ve fonksiyonelliğinin değerlendirebilmesi amacıyla geçerliliği ve güvenilirliği sağlanmış çeşitli testler ve ölçekler tanımlanmıştır. Bunlardan en sık kullanılanları Berg Fonksiyonel Denge Skalası, Fonksiyonel Uzanma Testi, Zamanlı Kalk ve Yürü Testidir (4). Bu testlerin yanı sıra Türkçe'ye uyarlanmış olan "Alt Ekstremite Fonksiyonel Ölçeği", fonksiyonelliğin objektif değerlendirilmesi için ideal bulunmuştur (15).

$\mathrm{Bu}$ çalışmanın amacı; 65 yaş üstü kadınlarda alt ekstremitede yer alan 12 farklı kas grubuna ait kuvvetin, denge ve alt ekstremite fonksiyonları ile ilişkisini belirlemektir.

\section{GEREÇ ve YÖNTEMLER}

Çalışmaya, üçüncü basamak sağlık kuruluşuna çeşitli sebeplerle başvuran 72 kadın gönüllü olarak katıldı. Araştırma grubunun kadın cinsiyetten seçilmesinin sebebi, kadınlarda düşme sonrası osteoporoza bağlı kırıkların daha erken yașta görülmesiydi. Gönüllülere, çalışmanın içeriği, amacı 
ve uygulanışı hakkında bilgi verildi. Çalıșma boyunca Helsinki Bildirgesi'ne uygun hareket edildi.

Çalışmaya dahil olma kriterleri; 65 yaş üstünde kadın olmak, yardımcı cihaza ihtiyaç duymadan bağımsız olarak yürüyebilmek, Standardize Mini Mental Test Skoru uygulandığında 24 ve üzeri puan almaktı. Çalışmaya katılan bireyler, bu güne kadar düzenli olarak egzersiz yapmayan sedanter kişilerdi.

Ciddi görme kaybının olması, alt ekstremitede geçirilmiş kas-iskelet sistemi yaralanması olması, test protokolünün uygulanmasını engelleyecek veya kısıtlayabilecek bel ağrısı ve alt ekstremite patolojisi gibi ortopedik, vestibüler, nörolojik veya zihinsel bir probleme sahip olunması, postüral hipotansiyon tanısının olması, kooperasyon kurulamaması, akut bir hastalığın iyileşme döneminde olunması dışlama kriteri olarak belirlendi $(4,16)$.

$\mathrm{Bu}$ kriterlere göre seçilen katılımcıların yaşı, vücut ağırlığı, boy uzunluğu ve son bir yıl içindeki düşme öyküsü sorgulanarak kaydedildi (17). Katılımcılara Berg Fonksiyonel Denge Skalası, Fonksiyonel Uzanma Testi, Zamanlı Kalk ve Yürü Testi ve Alt Ekstremite Fonksiyonel Ölçeği uygulandı. Alt ekstremitede kas kuvveti ölçümü, deneyimli fizyoterapist tarafından dijital el dinamometresi (Lafayette Instruments, Lafayette, IN, ABD) kullanılarak yapıldı.

\section{Ölçümler (uygulama sırasıyla)}

1. Alt Ekstremite Fonksiyonel Ölçeği, bireylerin alt ekstremite fonksiyonlarını, yeteneklerini ve aktivite kısıtlılıklarını değerlendirmek amacıyla geliştirilen, Türkçe geçerliliği sağlanmış ve 0-80 arasında puanlandırılan bir ankettir (15). Bu anket, görüşme sırasında yüz yüze dolduruldu.

2. Berg Fonksiyonel Denge Skalası, yaşlılarda ve nörolojik patolojisi olan hastalarda dengenin değerlendirilmesi için kullanılmaktadır. Bu skalada, otururken ayağa kalkma, desteksiz ayakta durma, destekli oturma, ayakta iken oturma, transferler, desteksiz ayakta durma, öne uzanma, eğilip yerden cisim alma, gövdeyi çevirme/dönme, basamak inip çıkma, tandem duruşu, tek ayak üzerinde durma gibi günlük hayatta sıklıkla kullanılan aktiviteleri ayrıntısı ile incelemektedir (3). Bu skala, deneyimli fizyoterapistin gözetiminde uygulanarak 0-56 puan arasında puanlandı.

3. Fonksiyonel Uzanma Testi, öne doğru olan stabiliteyi incelemek için geliştirilen bir testtir. Test sırasında katılımcıların ayaklarının yer ile temasını kesmeden uzanabildikleri kadar öne uzanmaları istendi (9). Bu test, katılımcılara üç kez uygulandı ve ölçülen en iyi değer analizler için kullanıldı.

4. Zamanlı Kalk ve Yürü Testi, dinamik dengenin, yürüme hızının ve mobilitenin hızlıca değerlendirilebildiği pratik bir testtir. $\mathrm{Bu}$ testte, katılımcıdan sandalyenin kollarına tutunmaksızın oturduğu yerden kalkması, 3 m yürüdükten sonra herhangi bir yere dokunmaksızın geri dönmesi, sandalyeye doğru yürüyerek tekrar oturur pozisyona geçmesi istendi (18). Test $10 \mathrm{dk}$ dinlenme arası verilerek iki kez uygulandı ve en iyi değer değerlendirmeye alındı.

5. Kas kuvveti ölçümü'nde, yașlıların izometrik kas kuvveti ölçümü için, geçerliliği sağlanan dijital el dinamometresi alt ekstremite kas kuvvetlerinin ölçümlerinde kullanıldı $(6,19)$. Çalışmada alt ekstremitede yer alan 12 farklı grup kas için kuvvet ölçümü yapıldı. Bu kaslar; kalça fleksörleri, kalça ekstansörleri, kalça abdüktörleri, kalça addüktörleri, kalça internal rotatörleri, kalça eksternal rotatörleri, diz fleksörleri, diz ekstansörleri, ayak bileği dorsifleksörleri, ayak bileği plantar fleksörleri, ayak bileği invertörleri ve ayak bileği evertörleriydi. Ölçümler sırasında katılımcıların maksimum izometrik kasılmayı $5 \mathrm{~s}$ süreyle yapmaları istendi (4). Alt ekstremite kas kuvveti ölçümleri sağ ve sol taraf olarak ayrı ayrı ve üç kez tekrar edildi. Sağ ve sol taraftaki en iyi değerin ortalaması analizlerde kullanıldı. Ölçüm pozisyonları ile ilgili ayrıntı Tablo 1'de verildi. 
Tablo 1. İzometrik alt ekstremite kas kuvveti ölçüm pozisyonları

\begin{tabular}{|c|c|c|}
\hline Kas grupları & Test pozisyonu & Dinamometrenin yeri \\
\hline \multicolumn{3}{|l|}{ Kalça kasları } \\
\hline Fleksörler & $\begin{array}{l}\text { Uyluk koltuktan } 10^{\circ} \\
\text { fleksiyona }\end{array}$ & Uyluk distali, diz proksimali \\
\hline Ekstansörler & $\begin{array}{l}\text { Diz ekstansiyonda iken kalça } \\
10^{\circ} \text { ekstansiyona }\end{array}$ & $\begin{array}{l}\text { Uyluk posterioru, diz } \\
\text { proksimali }\end{array}$ \\
\hline Abdüktörler & $\begin{array}{l}\text { Prone pozisyonda diz düz } \\
\text { iken kalça } 30^{\circ} \text { abdüksiyona }\end{array}$ & Femur lateral epikondili \\
\hline Addüktörler & $\begin{array}{l}\text { Prone pozisyonda kalça } 30^{\circ} \\
\text { abdüksiyonda }\end{array}$ & $\begin{array}{l}\text { Uyluk mediali, femur medial } \\
\text { epikondili }\end{array}$ \\
\hline İnternal rotatörler & $\begin{array}{l}\text { Otururken nötral kalça } \\
\text { pozisyonunda }\end{array}$ & $\begin{array}{l}\text { Medial malleol proksimali, } \\
\text { tibia mediali }\end{array}$ \\
\hline $\begin{array}{l}\text { Eksternal } \\
\text { rotatörler }\end{array}$ & $\begin{array}{l}\text { Otururken nötral kalça } \\
\text { pozisyonunda }\end{array}$ & $\begin{array}{l}\text { Lateral malleol proksimali, } \\
\text { fibula laterali }\end{array}$ \\
\hline \multicolumn{3}{|l|}{ Diz kasları } \\
\hline Fleksörler & Diz $90^{\circ}$ fleksiyonda & $\begin{array}{l}\text { Bacak posterodistali, ayak } \\
\text { bileği proksimali }\end{array}$ \\
\hline Ekstansörler & Diz $80^{\circ}$ fleksiyonda & $\begin{array}{l}\text { Bacak anterodistali, ayak } \\
\text { bileği proksimali }\end{array}$ \\
\hline \multicolumn{3}{|l|}{ Ayak bileği kasları } \\
\hline Dorsifleksörler & Topuk zeminle temasta & $\begin{array}{l}\text { Ayağın distal, medial, dorsal } \\
\text { yüzü }\end{array}$ \\
\hline Plantarfleksörler & Prone nötral pozisyonda & Ayağın plantar yüzü \\
\hline İnvertörler & Prone nötral pozisyonda & $\begin{array}{l}\text { Ayak medial yüzü, proksimal } \\
\text { metatarsofalangeal eklem }\end{array}$ \\
\hline Evertörler & Prone nötral pozisyonda & $\begin{array}{l}\text { Ayak lateral yüzü, proksimal } \\
\text { metatarsofalangeal eklem }\end{array}$ \\
\hline
\end{tabular}

\section{İstatistiksel Analiz}

Veriler SPSS v20.0 paket programı kullanılarak analiz edildi. Bağımsız değişkenlerin birbiriyle ilişkileri Pearson korrelasyon analizi aracılığında değerlendirildi. Düşme öyküsü olan ve olmayan grupların verilerini karşılaştırmak için MannWhitney U test kullanıldı. İstatistiksel anlamlılık düzeyi olarak $\mathrm{p}<0.05$ değeri alındı. Sonuçlar, ortalama \pm standart sapma (en düşük-en yüksek değer) olarak verildi.

\section{BULGULAR}

Çalışmaya katılan kadınların (n:72) yaş ortalaması $67.1 \pm 3.1$ yll, boy uzunluğu $157.0 \pm 4.9 \mathrm{~cm}$, vücut ağırlığı $71.4 \pm 12.1 \mathrm{~kg}$, vücut kütle indeksi $28.0 \pm 4.5$ $\mathrm{kg} / \mathrm{m}^{2}$ olarak saptandı. Katılımcıların sekizi (\%11.1) son bir yılda düşme öyküsüne sahipti. Berg Fonksiyonel Denge Skalası 49.7 \pm 5.6 (3256) puan, Fonksiyonel Uzanma Testi $23.2 \pm 5.7$ (12-38) cm, Zamanlı Kalk ve Yürü Testi 10.8 \pm 4.4 (4.2-33.3) s ve Alt Ekstremite Fonksiyonel Ölçeği $39.6 \pm 15.0 \quad(12-79)$ puan değerleri verdi. Katılımcların alt ekstremite kas kuvveti değerleri Tablo 2'de özetlenmektedir. 
Tablo 2. Alt ekstremite kas kuvveti sonuçları (Değerler kgf olarak; n:72)

\begin{tabular}{lrcc}
\hline Kas grupları & \multicolumn{1}{c}{$\mathbf{X} \pm \mathbf{S D}$} & En düşük & En yüksek \\
\hline Kalça fleksörleri & $9.8 \pm 3.3$ & 4.6 & 18.1 \\
Kalça ekstansörleri & $20.7 \pm 5.5$ & 7.6 & 28.3 \\
\hline Kalça abdüktörleri & $6.7 \pm 3.4$ & 3.0 & 18.9 \\
\hline Kalça addüktörleri & $8.0 \pm 2.9$ & 3.1 & 14.8 \\
Kalça internal rotatörleri & $6.2 \pm 3.3$ & 2.8 & 15.3 \\
\hline Kalça eksternal rotatörleri & $5.7 \pm 2.5$ & 2.5 & 14.8 \\
Diz fleksörleri & $10.1 \pm 2.9$ & 3.7 & 13.3 \\
\hline Diz ekstansörleri & $13.7 \pm 4.6$ & 5.1 & 20.9 \\
\hline Ayak bileği dorsifleksörleri & $6.3 \pm 2.7$ & 2.7 & 17.5 \\
\hline Ayak bileği plantarfleksörleri & $12.4 \pm 3.0$ & 4.3 & 17.3 \\
\hline Ayak bileği invertörleri & $5.3 \pm 1.6$ & 2.3 & 9.8 \\
\hline Ayak bileği evertörleri & $5.2 \pm 1.4$ & 2.7 & 9.2 \\
\hline
\end{tabular}

$\mathrm{X} \pm \mathrm{SD}$ : ortalama \pm standart sapma; kgf: kilogram-kuvvet

Yaşın alt ekstremite fonksiyonu ve denge ile ilişkisi incelendiğinde; yaş ile Berg Denge Skalası sonuçları ( $\mathrm{r}=-0.507, \mathrm{p}<0.01)$, Zamanlı Kalk ve Yürü Testi performansı $(\mathrm{r}=0.425, \mathrm{p}<0.01)$, Fonksiyonel Uzanma Testi sonuçları ( $\mathrm{r}=-0.273$, $\mathrm{p}<0.05)$, Alt Ekstremite Fonksiyonel Skalası sonuçları ( $\mathrm{r}=-0.334$, $\mathrm{p}<0.01$ ) arasında istatistiksel olarak anlaml ilişkisi bulundu. Yaşın alt ekstremite kas kuvveti ile ilişskisi incelendiğinde ise; yaş ile kalça fleksiyon $(\mathrm{r}=-0.313, \mathrm{p}<0.05)$, kalça ekstansiyon $(\mathrm{r}=-0.510$, $\mathrm{p}<0.01)$, kalça abdüksiyon $(\mathrm{r}=-0.288, \mathrm{p}<0.01)$, kalça addüksiyon $(\mathrm{r}=-0.267, \mathrm{p}<0.05)$, kalça internal rotasyon $(\mathrm{r}=-0.128, \mathrm{p}<0.05)$, kalça eksternal rotasyon $(\mathrm{r}=-0.272, \mathrm{p}<0.05)$, diz fleksiyon $(\mathrm{r}=$ $-0.302, p<0.05)$, diz ekstansiyon $(r=-0.773, p<0.01)$, ayak bileği dorsifleksiyon ( $\mathrm{r}=-0.773, \mathrm{p}<0.01)$, ayak bileği plantarfleksiyon ( $\mathrm{r}=-0.259, \mathrm{p}<0.05)$, ayak bileği inversiyon $(r=-0.254, \mathrm{p}<0.05)$ ve ayak bileği eversiyon $(r=-0.286, p<0.05)$ kas kuvvetleri ile istatistiksel olarak anlamlı ve negatif ilişkisi bulundu.

Alt Ekstremite Fonksiyonel Ölçeği sonuçlarının; kalça fleksiyon ( $\mathrm{r}=0.485)$, kalça abdüksiyon $(\mathrm{r}=0.464)$, kalça internal $(\mathrm{r}=0.456)$ ve eksternal rotasyon $(\mathrm{r}=0.467)$, diz fleksiyon $(\mathrm{r}=0.520)$, ayak bileği plantarfleksiyon $(\mathrm{r}=0.445)$, inversiyon $(\mathrm{r}=$ $0.496)$ ve eversiyon ( $r=0.523$ ) kas kuvvetleri ile pozitif yönlü orta düzeyde istatistiksel olarak anlamlı ilişkisi vardı $(\mathrm{p}<0.05)$. Ayrıca, kalça kalça addüksiyon ( $r=0.634)$ ve ayak bileği dorsifleksiyon ( $\mathrm{r}=0.734$ ) arasında pozitif yönlü yüksek düzeyde; kalça $(r=0.880)$ ve $\operatorname{diz}(r=0.848)$ ekstansiyon kas kuvvetleri arasında pozitif yönlü çok yüksek düzeyde istatistiksel olarak anlamlı ilişkisi bulundu $(\mathrm{p}<0.05)$, (Tablo 3). Berg Fonksiyonel Denge Skalası sonuçları ile kalça ekstansiyon ( $\mathrm{r}=0.339)$, kalça addüksiyon $(\mathrm{r}=$ 0.305), kalça eksternal rotasyon ( $\mathrm{r}=0.256)$, diz ekstansiyon ( $\mathrm{r}=0.394)$, ayak bileği dorsifleksiyon $(r=0.282)$, inversiyon $(r=0.364)$ ve eversiyon $(\mathrm{r}=0.332)$ kas kuvveti arasında pozitif yönlü zayıf düzeyde istatistiksel olarak anlamlı ilişki saptandi $(\mathrm{p}<0.05)$, (Tablo 3$)$.

Fonksiyonel Uzanma Testi ile kalça ekstansiyon $(\mathrm{r}=0.158)$, kalça addüksiyon $(\mathrm{r}=0.132)$ ve ayak bileği plantarfleksiyon ( $\mathrm{r}=0.145)$ kas kuvvetleri arasında pozitif yönlü çok zayıf düzeyde; kalça fleksiyon ( $\mathrm{r}=0.303)$, diz ekstansiyon ( $\mathrm{r}=0.342)$, ayak bileği dorsifleksiyon ( $\mathrm{r}=0.265)$, inversiyon 
Tablo 3. Alt ekstremite kas kuvvetlerinin denge ve fonksiyonellik ile ilişkisi (n:72)

\begin{tabular}{lllll}
\hline & BDS (r) & ZKYT (r) & FUT (r) & AEFÖ (r) \\
\hline Kalça fleksörleri & 0.168 & $-0.346^{* *}$ & $0.303^{*}$ & $0.485^{*}$ \\
\hline Kalça ekstansörleri & $0.339^{* *}$ & $-0.502^{* *}$ & $0.158^{*}$ & $0.880^{* *}$ \\
\hline Kalça abdüktörleri & 0.082 & -0.032 & 0.051 & $0.464^{*}$ \\
\hline Kalça addüktörleri & $0.305^{*}$ & -0.047 & $0.132^{*}$ & $0.634^{* *}$ \\
\hline Kalça internal rotatörleri & 0.206 & -0.050 & 0.110 & $0.456^{*}$ \\
\hline Kalça eksternal rotatörleri & $0.256^{*}$ & -0.014 & 0.168 & $0.467^{*}$ \\
\hline Diz fleksörleri & 0.160 & -0.118 & 0.118 & $0.520^{*}$ \\
\hline Diz ekstansörleri & $0.394^{* *}$ & $-0.426^{* *}$ & $0.342^{* *}$ & $0.848^{* *}$ \\
\hline Ayak bileği dorsifleksörleri & $0.282^{*}$ & $-0.613^{* *}$ & $0.265^{*}$ & $0.734^{* *}$ \\
\hline Ayak bileği plantarfleksörleri & 0.193 & -0.009 & $0.145^{*}$ & $0.445^{*}$ \\
\hline Ayak bileği invertörleri & $0.364^{* *}$ & $-0.282^{*}$ & $0.350^{* *}$ & $0.496^{*}$ \\
\hline Ayak bileği evertörleri & $0.332^{* *}$ & -0.210 & $0.342^{* *}$ & $0.523^{*}$ \\
\hline
\end{tabular}

BDS: Berg fonksiyonel denge skalası, ZKYT: zamanlı kalk ve yürü testi, FUT: fonksiyonel uzanma testi, AEFS: alt ekstremite fonksiyonel ölçeği. İstatistiksel anlamlılık; *: p<0.05, **: $\mathrm{p}<0.01$; korrelasyon düzeyi $\mathrm{r}<0.20$ : çok zayıf iliş̧ki, $\mathrm{r}$ : 0.20-0.39: zayıf ilişki, r: 0.40-0.59: orta ilişki, r: 0.60-0.79: yüksek ilişki, r>0.80: çok yüksek ilişki.

Tablo 4. Düşme öyküsü olan ve olmayan grupların fonksiyonel sonuçlarının karşılaştırılması (X $\pm S S$ )

\begin{tabular}{lccl}
\hline & $\begin{array}{c}\text { Düşme öyküsü } \\
\text { olan (n:8) }\end{array}$ & $\begin{array}{c}\text { Düşme öyküsü } \\
\text { olmayan (n:64) }\end{array}$ & p değeri \\
\hline Kalça fleksörleri (kgf) & $9.4 \pm 1.9$ & $10.3 \pm 1.7$ & 0.341 \\
\hline Kalça ekstansörleri (kgf) & $17.6 \pm 5.4$ & $23.8 \pm 6.6$ & $\mathbf{0 . 0 3 9 *}$ \\
\hline Kalça abdüktörleri (kgf) & $6.3 \pm 1.8$ & $7.0 \pm 2.2$ & 0.387 \\
\hline Kalça addüktörleri (kgf) & $6.3 \pm 1.7$ & $9.8 \pm 5.3$ & 0.054 \\
\hline Kalça internal rotatörleri (kgf) & $5.8 \pm 2.4$ & $6.6 \pm 2.4$ & 0.448 \\
\hline Kalça eksternal rotatörleri (kgf) & $5.3 \pm 1.8$ & $6.1 \pm 2.2$ & 0.385 \\
\hline Diz fleksörleri (kgf) & $9.1 \pm 2.8$ & $11.1 \pm 2.7$ & 0.108 \\
\hline Diz ekstansörleri (kgf) & $12.6 \pm 1.9$ & $14.6 \pm 1.7$ & $\mathbf{0 . 0 2 1 *}$ \\
\hline Ayak bileği dorsifleksörleri (kgf) & $4.9 \pm 1.6$ & $7.7 \pm 3.2$ & $\mathbf{0 . 0 3 0 *}$ \\
\hline Ayak bileği plantarfleksörleri (kgf) & $10.9 \pm 2.9$ & $13.8 \pm 3.7$ & 0.061 \\
\hline Ayak bileği invertörleri (kgf) & $5.1 \pm 1.8$ & $5.6 \pm 1.2$ & 0.622 \\
\hline Ayak bileği evertörleri (kgf) & $5.2 \pm 1.5$ & $5.3 \pm 2.0$ & 0.895 \\
\hline BDS (puan) & $48.3 \pm 8.0$ & $51.1 \pm 2.9$ & 0.921 \\
\hline ZKYT (s) & $13.4 \pm 5.3$ & $8.3 \pm 2.2$ & $\mathbf{0 . 0 0 6 *}$ \\
\hline FUT (cm) & $20.7 \pm 5.1$ & $25.7 \pm 3.2$ & $\mathbf{0 . 0 1 3 *}$ \\
\hline AEFö (puan) & $35.7 \pm 14.3$ & $43.6 \pm 14.6$ & 0.13 \\
\hline
\end{tabular}

BDS: Berg fonksiyonel denge skalası, ZKYT: zamanlı kalk ve yürü testi, FUT: fonksiyonel uzanma testi, AEFS: alt ekstremite fonksiyonel ölçeği. İstatistiksel anlamlllı;; *:p<0.05. 
$(\mathrm{r}=0.35)$ ve eversiyon $(\mathrm{r}=0.342)$ kas kuvvetleri arasında ise pozitif yönlü zayıf düzeyde istatistiksel olarak anlamlı ilişki belirlendi ( $\mathrm{p}<0.05)$, (Tablo 3).

Zamanlı Kalk ve Yürü Testinin; kalça fleksiyon $(\mathrm{r}=-0.346)$, ayak bileği inversiyon $(\mathrm{r}=-0.282)$ kas kuvvetleri ile negatif yönlü zayıf düzeyde; kalça $(\mathrm{r}=-0.502)$ ve diz ekstansiyon $(\mathrm{r}=-0.426)$ kas kuvvetleri ile negatif yönlü orta düzeyde; ayak bileği dorsifleksiyon ( $\mathrm{r}=-0.613)$ kas kuvveti ile negatif yönlü yüksek düzeyde istatistiksel olarak anlamlı ilişkisi vardı $(\mathrm{p}<0.05)$, (Tablo 3).

Düşme öyküsü olan ve olmayan grupların karşılaştırılması sonucunda; kalça ve diz ekstansör kasları ile ayak bileği dorsifleksör kas gruplarında, Zamanlı Kalk ve Yürü Testinde ve Fonksiyonel Uzanma Testinde istatistiksel anlamlı fark tespit edildi ( $\mathrm{p}<0.05)$, (Tablo 4). Düşme öyküsü olanların fonksiyonel sonuçları daha kötüydü.

\section{TARTIȘMA}

Elde edilen sonuçlar, alt ekstremitede yer alan tüm kas gruplarının denge ve/veya fonksiyonellikte rol oynadığını göstermektedir. Denge için özellikle distal eklemi stabilize eden kaslar ile ekstansör bölge kasları görev almaktadır. Postüral stabilizasyonda ve mobilitede özellikle kalça ve diz ekstansörleri ile ayak bileği dorsifleksörleri önemlidir. Anteriora olan postüral hareketlerin kontrolünde ayak bileği çevresinde yer alan kas kuvvetlerinin gerekli olduğu görülmektedir. Alt ekstremite fonksiyonlarında en önemli olan kaslar ise kalça ve diz ekstansörleridir.

Yaşın ilerlemesi ile birlikte kas fonksiyonlarının, yürüme hızının ve kas kuvvetinin azaldığı bilinmektedir (16). Henüz herhangi bir engeli bulunmayan yaşlıların alt ekstremitelerindeki fonksiyonellik seviyesi, ileride gelişebilecek olan düșmeyi ve preklinik evredeki engelliliği öngörmede yararlı bulunmaktadır (20). Bu çalışmada da alt ekstremite fonksiyonlarını değerlendirmek amaciyla Alt Ekstremite Fonksiyonel Ölçeği kullanıldı ve bu ölçek sonuçlarının alt ekstremite kas gruplarının kuvveti ile ilişkisi gösterildi.
Düşme öyküsünün yaşlı popülasyonda artması, düşmenin kas kuvveti ve fonksiyonlarla olan ilişkisinin öngörülebilmesi birçok çalışmanın tasarlanmasına neden olmuştur. Konuya ilișkin literatür incelendiğinde, düșmenin nedenlerini belirleyebilmek amacıyla düşme riskinin denge, fonksiyonellik, kas kuvveti, mobilite gibi farklı parametrelerle iliş̧isinin araştırılmış olduğu görülmektedir $(21,22)$.

Roma ve arkadaşları, ayak bileği dorsifleksiyon kas kuvvetinin Berg Fonksiyonel Denge Skalası ve Zamanlı Kalk ve Yürü Testi sonuçları ile ilişkisini inceledikleri çalışmalarında, 65 yaş üstündeki 100 kadından son bir yıl içinde düşme öyküsü olanların el dinamometresi ile ölçülen ayak bileği izometrik dorsifleksiyon kas kuvvetini 10.2 kgf, düşme öyküsü olmayanların dorsifleksiyon kas kuvvetini ise 11.5 kgf olarak belirlemişlerdir (21). Düşme öyküsü olanların Berg Fonksiyonel Denge Skalası puanı 42.3 iken Zamanlı Kalk ve Yürü Testi sonucu 17.6 s olarak ölçülmüştür. Düşme öyküsü olmayanların aynı testlerdeki ölçüm sonuçları ise sırasıyla 50.2 puan ve 10.6 s olarak bulunmuştur. Bu çalışmada, kas kuvvetinin, denge ve ambülatuar fonksiyon ile orta düzeyde ilişkisi belirlenmiş, bu ilişki düşme öyküsü olan/olmayan grup arasında fark oluşturmamıştır (21). Çalışmamızda sunulan ayak bileği dorsifleksör kas kuvveti değerleri daha düşük olmakla birlikte, Berg Fonksiyonel Denge Skalası ve Zamanlı Kalk ve Yürü Testi sonuçları düşme öyküsü olmayan grubun sonuçlarına benzer bulundu.

Farklı bir çalışmada düşme öyküsü olan bireylerin Berg Fonksiyonel Denge Skalası 49.0 puan, Zamanlı Kalk ve Yürü Testi sonucu $13.2 \mathrm{~s}$, Fonksiyonel Uzanma Testi $27.7 \mathrm{~cm}$; düşme öyküsü olmayan bireylerde ise bu değerler sirasıyla 49.9 puan, $11.1 \mathrm{~s}$ ve $29.3 \mathrm{~cm}$ olarak belirlenmiş, alt ekstremitenin 12 farklı kas grubunun incelendiğinde bu çalışmada ayak bileği çevresindeki kas gruplarının fonksiyonel denge puanları ile olan ilişkisi bulunmuştur (4). Denge ve postüral kontrolde ayak bileğinin dizden daha fazla rol aldığı ifade edilmiştir (23). Çalışmamızda gözlenen fonksiyonel uzanma miktarı daha düşüktür, ancak alt ekstremite fonksiyonlarının 
değerlendirildiği tüm parametrelerin kas kuvveti ile ilişkisi belirlenmiştir.

Buradaki çalışmada, denge ve fonksiyonel mobiliteyi değerlendirmek için literatürde sıkça kullanılan ölçüm araçları kullanılmış, anlamlı sonuçlar elde edilmiştir. Düşme öyküsü olan ve olmayan gruplar karşılaştırıldığında, kalça ve diz ekstansör kasları ile ayak bileği dorsifleksör kas gruplarında, Zamanlı Kalk ve Yürü Testinde ve Fonksiyonel Uzanma Testi sonuçlarında anlamlı farklılıklar bulundu. Ancak düşme öyküsü olan grupta az sayıda bireyin bulunması analizin gücünü zayıflatmaktadır. Bu nedenle daha geniş olgu gruplarında karşılaştırmanın yapıldığg ileri çalışmalara gereksinim duyulmaktadır.

Wang ve arkadaşları, kalça fleksör, kalça abdüktör, diz ekstansör ve ayak bileği dorsifleksör kas gruplarının el dinamometresi ile ölçülen sonuçlarının fonksiyonel mobilite ile korrelasyon gösterdiğini bulmuşlardır (22). Lee ve ark., yaşlı kadınlarda Y Denge Skalası ile diz fleksör kasları ve kalça abdüktör kasları arasında, orta yaşlı bireylerde ise diz fleksör kasları ve kalça ekstansör kasları arasında pozitif korrelasyon belirlemişlerdir (24). Vakalarımızın çok ileri yaşlı olmaması, sonuçların orta yaşlı bireyler için raporlanan sonuçlarla daha fazla uyum göstermesini açıklayabilmektedir.

Sandalyede Otur-Kalk Testi gibi fonksiyonel değerlendirmelerin, stabilite indeksi ile orta düzeyde negatif korrelasyonu bulunur (17). Fonksiyonel testlerin yanı sıra, diz ekstansör ve kalça addüktör kas kuvvetinin stabilite ile korrelasyonunun belirlendiği bir çalışmada, 60 yaşın üstündeki bireylerin el dinamometresi ile ölçülen kas kuvveti değerleri kalça fleksörlerinde 6.06 kgf, ekstansörlerinde 5.79 kgf, abdüktörlerinde 6.06 kgf, addüktörlerinde $5.24 \mathrm{kgf} ; \quad \mathrm{diz}$ fleksörlerinde $5.84 \mathrm{kgf}$, ekstansörlerinde 5.71 kgf; ayak bileği plantar fleksörlerinde $7.31 \mathrm{kgf}$, dorsifleksörlerinde 5.33 kgf olarak saptanmıştır (7). Kas kuvveti için verilen bu değerler, çalışmamızda sunulan verilerden daha düşüktür. $\mathrm{Bu}$ durumun, katılımclların ve ölçüm yöntemlerinin farklılı göstermesinden kaynaklandığı düşünülmüștür.
Çalışmamızda, Zamanlı Kalk ve Yürü Testi ile değerlendirilen fonksiyonel mobilite düzeyinin; kalça fleksiyon, ayak bileği inversiyon kas kuvvetleri ile negatif yönlü zayıf düzeyde; kalça ve diz ekstansiyon kas kuvvetleri ile negatif yönlü orta düzeyde; ayak bileği dorsifleksiyon kas kuvveti ile negatif yönlü yüksek düzeyde istatistiksel olarak anlamlı ilişkisi olduğu saptandı. Cebolla ve arkadaşları, alt ekstremite kas kuvvetinin artmasının $6 \mathrm{dk}$ Yürüme Testi, Otur-Uzan Testi, 8 Adım Yürü Testi ve 30 s OturKalk Testi gibi fonksiyonel testlerdeki başarıyı arttırdığını saptamışlardır. Son bir yılda düşme öyküsü olan bireylerin daha düșük alt ekstremite kuvvetine, yürüme performansına ve dinamik dengeye sahip olduklarını belirlemişlerdir (25). Evin içinde görülen düşmelerin incelendiği bir diğer çalışmada da diz ekstansiyon kuvvetindeki kayıplarla düșme riski bağlantılı bulunmuștur (26). Ikezoe ve arkadaşları, düşmeden koruyacak olan diz ekstansör kas kuvveti değerinin 1.28 $\mathrm{Nm} / \mathrm{kg}$ olduğunu raporlamış (27); düşme riskinin azaltılabilmesi için yaşlı bireylere diz ekstansör kas kuvveti ve denge egzersizleri uygulanmasını önerilmiştir $(17,26,28,29)$.

Egzersiz uygulamalarının sonuçlarını inceleyen prospektif tasarımlı bir çalıșmada, yaşlıların 14 hafta boyunca progresif direnç egzersizi uygulamalarının, düşme riski ile ilişkili bulunan fonksiyonel uzanma ve zamanlı kalk ve yürü testi sonuçlarını geliştirdiği ifade edilmektedir. Fonksiyonel performansın artışı ve düşmeden korunmak için kas kuvvetinin önemli olduğu vurgulanmaktadır (9). Diz ekstansiyon ve fleksiyon kas kuvvetinin izokinetik test cihazı ile belirlendiği ve progresif egzersizin etkinliğinin incelendiği bir diğer çalışmada ise egzersiz programının 80 yaşının üstündeki bireylerin fonksiyonel performansını arttırdı $\breve{g}_{1}$, ancak fonksiyonel yeteneklerdeki gelişimin kas kuvvet ile bağlantısının kurulamadığı raporlanmıștır (18).

Yaşlılarda osteoartrit gibi diğer eklem patolojilerinin eklenmesi ile Otur-Kalk Testi sırasında ağırlık merkezinin transferi için daha fazla zaman gerekmektedir ve düşme riski ile bağlantılı bulunmaktadır. Düşme sıklığının 
azaltılması ve fonksiyonelliğin arttırılabilmesini garanti altına alabilmek için geriatrik bireylere yapılandırılmış egzersiz programları gibi gerekli tedavi stratejileri planlanmalıdır (3). Güncel literatürdeki bazı çalışmalar; yaşlılardaki fiziksel fonksiyonun izometrik ve izokinetik tork değerleri ile korrelasyonu bulunamasa da, maksimum torka ulaşma zamanı ve tork hızı gibi daha ayrıntılı analiz parametrelerinin fonksiyonellikle olan ilişkisi tanımlanmaya başlanmıştır (30).

Çalışmamızda kas kuvveti ile alt ekstremite fonksiyonları arasında anlamlı ilişkiler ortaya konulabilmiştir. Fakat düşme öykülü bireylerin sayısının az olması düşme öyküsü olan/olmayan bireyler arasındaki farkın belirlenmesini kısıtlamıştır. Benzer çalışmaların, aktivite düzeyi sayısal olarak belirlenmiș olan, düşme öyküsüne göre gruplandırılacak olgu gruplarında yürütülmesi ve karşılaștırma yapılması gerekmektedir.

\section{SONUÇ}

$\mathrm{Bu}$ çalışmada elde edilen sonuçlara göre, alt ekstremite kas kuvvetinin fonksiyonellik ile anlamlı ilişkisi belirlendi. Yaşlı kadınlarda fonksiyonelliğin, mobilitenin ve dengenin arttırılabilmesi, düşme riskinin azaltılabilmesi için alt ekstremitede yer alan tüm kas grupları kuvvetlendirilmelidir. Kuvvet egzersizleri sırasında, özellikle distal eklem çevresindeki kasların ve ekstansör bölge kaslarının alt ekstremite fonksiyonlarındaki anahtar rolü akılda tutulmalıdır.

\section{KAYNAKLAR}

1. Cruz-Jentoft AJ, Baeyens JP, Bauer JM, et al. Sarcopenia: European consensus on definition and diagnosis Report of the European Working Group on Sarcopenia in Older People. Age Ageing. 2010;39(4):412-23.

2. Granacher U, Gollhofer A, Hortobágyi $T$, et al. The importance of trunk muscle strength for balance, functional performance, and fall prevention in seniors: a systematic review. Sports Med. 2013;43(7):627-41.

3. Alencar MA, Arantes PMM, Dias JMD, et al. Muscular function and functional mobility of faller and non-faller elderly women with osteoarthritis of the knee. Braz J Med Biol Res. 2007;40(2):277-83.

4. Daubney ME, Culham EG. Lower-extremity muscle force and balance performance in adults aged 65 years and older. Phys Ther. 1999;79(12):1177-85.
5. Visser M, Deeg DJ, Lips P, et al. Skeletal muscle mass and muscle strength in relation to lower-extremity performance in older men and women. J Am Geriatr Soc. 2000;48(4):381-6.

6. Mijnarends DM, Meijers JM, Halfens RJ, et al. Validity and reliability of tools to measure muscle mass, strength, and physical performance in community-dwelling older people: a systematic review. JAMA. 2013;14(3):170-8.

7. Chandak P, Joshi V, Nimbhore S, et al. Correlation of lower extremity isometric muscle strength and balance performance in community-dwelling elderly females. Indian J Physiother Occup Ther. 2014;8(2):5-8.

8. Şahin Onat Ş, Ünsal Delialioğlu S, Özel S. Geriatrik popülasyonda dengenin fonksiyonel durum ve yașam kalitesi ile ilişkisi. Turk J Phys Med Rehab. 2014;60(2): 147-54.

9. Sousa N, Sampaio J. Effects of progressive strength training on the performance of the Functional Reach Test and the Timed Get-Up-and-Go Test in an elderly population from the rural north of Portugal. Am J Hum Biol. 2005;17(6):746-51.

10. Winter DA, Patla AE, Frank JS, et al. Biomechanical walking pattern changes in the fit and healthy elderly. Phys Ther. 1990;70(6):340-7.

11. Trombetti A, Reid KF, Hars M, et al. Age-associated declines in muscle mass, strength, power, and physical performance: impact on fear of falling and quality of life. Osteoporos Int. 2016;27(2):463-71.

12. Gross MM, Stevenson PJ, Charette SL, et al. Effect of muscle strength and movement speed on the biomechanics of rising from a chair in healthy elderly and young women. Gait Posture. 1998;8(3):175-85.

13. Kuo AD, Zajac FE. A biomechanical analysis of muscle strength as a limiting factor in standing posture. $J$ Biomechanics. 1993;26(Supp 1):137-50.

14. Binda SM, Culham EG, Brouwer B. Balance, muscle strength, and fear of falling in older adults. Exp Aging Res. 2003;29(2):205-19.

15. Çankaya M. Alt ekstremite fonksiyonel ölçeğinin Türkçe geçerlilik ve güvenilirlik çalışması. Muğla Sıtkı Koçman Üniversitesi, Sağllk Bilimleri Enstitüsü Yüksek Lisans Tezi. Muğla: Muğla Sıtkı Koçman Üniversitesi;2016.

16. Garcia PA, Dias J, Dias RC, et al. A study on the relationship between muscle function, functional mobility and level of physical activity in community-dwelling elderly. Rev Bras Fisioter. 2011;15(1):15-22.

17. Cho KH, Bok SK, Kim YJ, et al. Effect of lower limb strength on falls and balance of the elderly. Ann Rehabil Med. 2012;36:386-93.

18. Carmeli E, Reznick AZ, Coleman R, et al. Muscle strength and mass of lower extremities in relation to functional abilities in elderly adults. Gerontology. 2000;46(5):249-57.

19. Katoh M, Isozaki K, Sakanoue N, et al. Reliability of isometric knee extension muscle strength measurement using a hand-held dynamometer with a belt: a study of test-retest reliability in healthy elderly subjects. J Phys Ther Sci. 2010;22(4):359-63. 
20. Guralnik JM, Ferrucci L, Simonsick EM, et al. Lowerextremity function in persons over the age of 70 years as a predictor of subsequent disability. $N$ Engl J Med. 1995;332(9):556-62.

21. Roma AA, Chiarello LA, Barker SP, et al. Examination and comparison of the relationships between strength, balance, fall history, and ambulatory function in older adults. J Geriatr Phys Ther. 2001;24(2):21-30.

22. Wang CY, Olson S, Protas EJ, et al. Balance, lower extremity strength and flexibility as predictors of functional mobility in community-dwelling older adults. J Geriatr Phys Ther. 2001;24(3):28.

23. Fukagawa NK, Wolfson L, Judge J, et al. Strength is a major factor in balance, gait, and the occurrence of falls. J Gerontol A Biol Sci Med Sci. 1995;50(Special Issue):64-7.

24. Lee DK, Kang MH, Lee TS, et al. Relationships among the Y balance test, Berg Balance Scale, and lower limb strength in middle-aged and older females. Braz J Phys Ther. 2015; 19(3):227-34.

25. Cebolla EC, Rodacki AL, Bento PC. Balance, gait, functionality and strength: comparison between elderly fallers and non-fallers. Braz J Phys Ther. 2015;19(2): 146-51.

26. Asakawa Y, Ikezoe T, Hazaki K, et al. Relationship between falls and knee extension strength in the elderly. J Phys Ther Sci. 2001;8(2):45-8.

27. Ikezoe T, Asakawa Y, Tsutou A. The relationship between quadriceps strength and balance to fall of elderly admitted to a nursing home. J Phys Ther Sci. 2003;15(2):75-9.

28. Egerton T, Brauer SG, Cresswell AG. The immediate effect of physical activity on standing balance in healthy and balance-impaired older people. Australas J Ageing. 2009; 28(2):93-6.

29. Özsoy G, Özsoy İ, İlçin N, et al. Yaşlı bireylerde denge, fonksiyonel egzersiz kapasitesi ve periferal kas kuvveti arasındaki ilişki. SDÜ Sağlık Bilimleri Enstitüsü Dergisi. 2017;8 (1):1-5.

30. Altubasi IM. Is quadriceps muscle strength a determinant of the physical function of the elderly?. J Phys Ther Sci. 2015;27(10):3035-8. 